\title{
USO SOCIOCULTURAL DE GÊNEROS DISCURSIVOS POR ALUNOS BRASILEIROS E ALEMÃES
}

\author{
Alessandra Castilho Ferreira da Costa ${ }^{*}$
}

\begin{abstract}
Resumo: Este artigo apresenta os resultados da pesquisa, desenvolvida por Castilho da Costa (2005), sobre o uso sociocultural de gêneros discursivos por alunos brasileiros e alemães de escolas socialmente diferenciadas. A pesquisa busca responder à seguinte pergunta: Como alunos brasileiros $e$ alemães escolhem, usam e "formatam" quais gêneros discursivos ao comunicarem sobre conteúdos iguais ou parecidos? A análise baseia-se em um modelo de análise e interpretação de gêneros discursivos como entidades culturais, que possuem três dimensões: uma lingüística, uma cognitiva e uma pragmática. Na análise de dados foram levantados critérios para a identificação dos meios lingüísticos escolhidos pelos produtores (dimensão lingüística) e dos conhecimentos ativados quando da produção de gêneros discursivos (dimensão cognitiva) na realização de uma tarefa comunicativa (dimensão pragmática). Neste trabalho são apresentados alguns desses critérios: escolhas de gêneros discursivos, funções textuais modelos de argumentação, expressões do campo semântico da violência sensorialmente experenciada; e finalidade e concessividade. Os resultados mostram que o uso dos gêneros discursivos por alunos brasileiros e alemães é determinado por parâmetros culturais e sociais, tais como as tensões proximidade/distância, conteúdo abstrato/concreto, dentre outras. Para os Estudos do Texto e do Gênero Discursivo, o trabalho contribui com a comprovação da interculturalidade das escolhas de gênero.
\end{abstract}

Palavras-chave: Lingüística Textual, texto, gênero discursivo, cultura.

\section{Introdução}

A abordagem de gêneros discursivos tem ganhado relevância nas últimas décadas, tanto no Brasil quanto na Alemanha. A pesquisa em gêneros discursivos é um dos

\footnotetext{
* Doutora em Lingüística Germânica pela Martin-Luther-Universität Halle-Wittenberg e pós-doutoranda na Área de Filologia e Língua Portuguesa da USP.
} 
campos de maior interesse dentro dos Estudos do Texto. Além de uma pesquisa impregnada pela semiótica francesa, sobretudo pela Escola de Genebra, aprender e ensinar gêneros discursivos está no centro do interesse de pesquisas textuais voltadas à didática.

Os estudos de gêneros discursivos no Brasil têm sido marcados pelo diálogo entre tradições de pesquisa tão diferentes como a Lingüística Textual, a Análise do Discurso e a Semiótica, dentre outras. São destacadas, aqui, apenas três das principais tradições de pesquisa nos Estudos do Gênero no Brasil:

a tradição franco-suíça de pesquisa (ADAM 1990, BRONCKART 1985 E SCHNEUWLY 1993),

a tradição anglo-americana de pesquisa (SwAlEs 1990, BHATIA 1997, FAIRCLOUGH 1992) e

a tradição germânica de pesquisa (HEINEMANN \& VIEHWEGER 1991, VAN DIJK 1980, ANTOS 1997).

Embora a influência das idéias de BAKHTIN (1953) esteja presente em todas as três linhas de pesquisa, diferentes definições de gênero discursivo estão pressupostas em cada abordagem. Podemos apontar as seguintes definições de gêneros em algumas dessas abordagens:

gêneros como sequiências de macro-proposições (ADAM 1990, 1992)

gêneros como famílias de textos (SWALES 1990)

gêneros como megainstrumentos de aquisição e aprendizagem da língua (BRONCKART \& SCHNEUWLY 1985)

gêneros como formas de representação da realidade e de relações de poder entre indivíduos (FAIRCLOUGH 1992)

gêneros como formas de constituição do conhecimento (ANTOS 1997)

No centro do interesse da pesquisa em gêneros no Brasil estão não somente questões teóricas, mas também didáticas. A Lingüística do Gênero discursivo ${ }^{16}$ no Brasil ocupa-se predominantemente de problemas intraculturais e sociais do ensino de gêneros. Dado que o gênero é considerado como parte do processo comunicativo, há uma preocupação com as

\footnotetext{
${ }^{16}$ Consideramos a existência de uma Lingüística do Gênero Discursivo, área interdisciplinar que abrange todas as linhas de estudo de gêneros discursivos.
} 
condições de produção que acarretaram o seu aparecimento e com o seu valor didático como unidade básica da comunicação $\left(\mathrm{PCNs}^{17}\right)$. Em outras palavras: o uso tem um papel relevante na Lingüística do Gênero no Brasil.

Na Alemanha, a pesquisa de gêneros discursivos desempenha, como se sabe, desde o início um papel relevante (VAN DIJK 1980, BEAUGRANDE \& DRESSLER 1981, VIEHWEGER \& Heinemann 1991). Nos últimos anos, o foco de pesquisa em gêneros discursivos transportou-se para a questão da interculturalidade do gênero (FIX, HABSCHEID \& KLEIN 2001; ADAMZIK 2001b; DRESCHER 2002; KAISER 2002).

Procurando-se relacionar ambas linhas de pesquisas apesar de suas grandes diferenças, pode-se fazer as seguintes observações: no Brasil, o interesse está voltado à pesquisa dos discursos em que gêneros são utilizados, de um lado, e à questão do modo, como determinados destinatários usam determinados gêneros discursivos, a fim de atingir um objetivo comunicativo. Em outras palavras: A tônica da pesquisa em gêneros discursivos consiste em questões relativas ao uso adequado de certos gêneros discursivos em determinados contextos discursivos.

Já na Alemanha, questões classificatórias (SANDIG 1972, ROLF 1993) e a identificação de características estruturais eram o principal objeto de pesquisa nos anos $70 \mathrm{e}$ 80. Desde a virada do século, as questões de interculturalidade e contrastividade dos gêneros discursivos têm orientado a pesquisa em Lingüística Textual (ADAMZIK 2000, 2001, WARNKE 2001, KAISER 2002). Desse modo, o caráter dantes estrutural da perspectiva teórica dominante deu lugar a uma perspectiva predominantemente funcional. Para a Lingüística Intercultural do Gênero é o caráter histórico-social do gênero que determina seu funcionamento, i.e., gêneros discursivos desempenham papéis específicos em um determinado sistema discursivo, em uma determinada sociedade e em determinada época.

A conjugação de tão diferentes linhas de pesquisa favorece a dupla abordagem de gêneros discursivos e suas estruturas, de um lado, por meio da elaboração de uma perspectiva sociocultural do gênero discursivo, por outros, por meio do questionamento acerca do papel do uso do gênero discursivo em diferentes culturas. Essa abordagem deve ser empiricamente testada em um estudo intercultural de gêneros discursivos brasileiros e alemães.

\section{Gêneros discursivos alemães e brasileiros: um estudo intercultural}

Em termos concretos, a pergunta que orienta o presente trabalho é: Como alunos brasileiros e alemães escolhem, usam e "formatam" quais gêneros discursivos quando comunicam a respeito de temas semelhantes?

\footnotetext{
${ }^{17}$ Parâmetros Curriculares Nacionais (PCNs) são as propostas curriculares elaboradas pelo Ministério da Educação (MEC) que concretizam uma base nacional comum nos currículos de Ensino Fundamental e Médio.
} 

seguir:

De tal abordagem resultam as seguintes questões, apresentadas resumidamente a

$>$ Como determinadas tarefas comunicativas ("conteúdos") se refletem na escolha e na "formatação" de determinados gêneros discursivos? (questão intracultural)

$>$ Quais gêneros discursivos são escolhidos para a realização de tarefas lingüísticas semelhantes por produtores de textos de diferentes culturas? (questão intercultural)

$>$ Quais diferenças sociais existem dentro de uma determinada cultura quando da produção de gêneros discursivos? (diferenças sociais intraculturais)

$>$ Como tais diferenças intraculturais e sociais podem ser relacionadas em um estudo intercultural?

Importa, aqui, não somente uma comparação de características estruturais na composição de gêneros discursivos brasileiros e alemães. Mais que isso, busca-se, antes, indagar sobre as restrições típicas de uso que determinam a escolha de gêneros discursivos no Brasil e na Alemanha.

A fim de garantir a comparação temática, optou-se por um tema "global" e, portanto, não restrito a uma cultura somente: "Violência na Escola" (em alemão, "Gewalt in der Schule"). Alunos de $8^{a}$ série do Ensino Fundamental de escolas em São Paulo, Berlim e Hamburgo foram instados a se manisfestarem por escrito sobre o tema. Foi-lhes dada inteira liberdade na escolha do gênero discursivo a ser produzido. Em virtude desse procedimento, diferentes gêneros discursivos puderam ser coletados, tais como históriasem-quadrinhos, poemas e páginas de diário. Procurou-se, assim, observar os diferentes gêneros discursivos escolhidos por alunos brasileiros e alemães para a discussão de um mesmo tema.

As perguntas metodológicas que guiam esta análise intercultural do uso de gêneros discursivos podem ser assim resumidas:

1. Quais gêneros são produzidos por informantes brasileiros e alemães?

2. Em que medida tais gêneros possuem características diferentes nas duas culturas?

3. Em que níveis mostram-se as diferenças?

4. Em que medida o contexto escolar, social e cultural pode esclarecer eventuais diferenças na escolha de gêneros discursivos? 
Que contribuição teórica uma tal pesquisa de restrições típicas de uso e de escolha de gêneros discursivos pode trazer a um estudo intercultural? Partindo-se do uso e da escolha de gêneros discursivos, pode-se trazer luz à questão da culturalidade do gênero discursivo (isto é, do seu condicionamento à cultura) em uma tripla perspectiva:

1. Parece haver gêneros discursivos brasileiros e alemães, que apesar das diferentes línguas, mostram semelhanças de sentido ou, em vista da tradição latina comum, de denominações (narrativa, dissertação/ Dissertation). Contudo, a pesquisa em interculturalidade dá exemplos de denominações semelhantes que se mostram como "falsos cognatos". Quer dizer: apesar de uma aparente semelhança nas denominações, podem ser observadas diferenças nas características constitutivas e/ou em funções comunicativas relevantes.

2. Diferentes escolhas de gêneros discursivos podem estar ligadas com o fato de os respectivos modos típicos de uso estarem condicionados a restrições diferentes de uso. Isso vale, como ficará adiante mais claro, para a relação entre oralidade e escrita no Brasil e na Alemanha e, sobretudo, vale para as diferenças no âmbito da escrita: em escolas brasileiras, a distribuição da língua "literária" e da língua "científica" parece ser diferente de sua distribuição na Alemanha.

3. Uma terceira resposta à questão da culturalidade do gênero poderia ser a seguinte: produtores de textos de diferentes classes sociais receptam de modos diferentes o repertório de gêneros discursivos de suas respectiva língua materna, ou podem, ainda, ter diferentes capacidades de reproduzir um determinado conhecimento de gêneros para determinadas tarefas comunicativas. Tal aspecto é relevante para a questão das diferentes competências de gêneros discursivos, condicionadas por fatores sociais.

Como pano de fundo dessas observações, pode-se resumir a abordagem teóricometodológica do presente trabalho por meio das seguintes hipóteses inter-relacionadas:

\section{Hipóteses:}

1. Gêneros discursivos são marcados culturalmente por características $\boldsymbol{e}$ funções que os constituem, mas também por modos típicos de uso. Estudos 
interculturais devem considerar não somente diferenças estruturais, formais $e$ funcionais, mas também os modos típicos de uso.

2. Dado que as competências de gêneros são adquiridas e desenvolvidas em determinados ambientes sociais e culturais, existe uma constituição social e cultural dos modos típicos de uso dos gêneros discursivos.

3. Competências de gênero sociais e culturais podem refletir-se tanto em uma preferência na escolha de gêneros para conteúdos comparáveis quanto manifestar-se em uma aquisição e produção social- $e$ culturalmente diferentes de gêneros discursivos.

Essas três hipóteses a serem comprovadas na produção de gêneros na escola partem da premissa de que tanto a escolha quanto a (re)produção de gêneros discursivos permitem deduções interculturais do valor e do uso de gêneros discursivos em uma determinada cultura.

Texto e gênero discursivo são concebidos aqui como entidades culturais, embutidas em sistemas discursivos e que possuem três dimensões: uma cognitiva, uma pragmática e uma lingüística. Quer dizer: quando da produção de textos e, por conseguinte, de gêneros discursivos, conhecimentos são ativados e meios lingüísticos escolhidos a fim de se resolver uma tarefa comunicativa. Assim, são utilizados critérios cognitivos (semânticos), pragmáticos e lingüísticos (gramaticais). A análise dos dados procura responder às seguintes questões:

1. Quais são os conhecimentos ativados por escolares brasileiros e alemães ao produzirem textos sobre o tema "Violência na Escola"? (dimensão cognitiva)

2. Quais são as tarefas comunicativas a serem resolvidas, i.e., qual é o quadro de intenções predominantes? (dimensão pragmática)

3. Quais são os meios lingüísticos utilizados nessas produções? (dimensão lingüística)

Em função do caráter exploratório do presente trabalho, busca-se comprovar a relevância de diferentes parâmetros para a análise dos dados, de tal modo que a abordagem aqui utilizada norteia-se por pontos de vista analíticos heterogêneos.

A análise da dimensão pragmática pauta-se por critérios propostos pela abordagem sociológica (der sozialwissenschaftliche Ansatz): Para comprovar o ancoramento social de gêneros discursivos, LUCKMANN (1988:280) introduz o conceito de gerenciamento comunicativo (em alemão, kommunikativer Haushalt). Segundo Luckmann, os gêneros discursivos e tradições discursivas estão socialmente ancorados e 
exercem influência recíproca uns sobre os outros, pois fazem parte do sistema do gerenciamento comunicativo de uma sociedade (em alemão, kommunikativer Haushalt, vide LUCKMANN, 1988:285).

\section{O conceito de gerenciamento comunicativo}

Uma das principais características do conceito de gênero discursivo é o seu caráter histórico-social (BAKHTIN 1953), o qual determina o funcionamento e o próprio surgimento do gênero discursivo. Nesse sentido, AdAMzIK $(2000,2001,2002)$ propõe uma teoria de análise de gêneros discursivos que não se restrinja aos aspectos lingüístico-estruturais, mas que se volte ao "gerenciamento comunicativo" de uma sociedade. O conceito de "gerenciamento comunicativo" (em alemão, kommunikativer Haushalt), postulado por LUCKMANN (1988), abrange todos os processos comunicativos em uma sociedade. LUCKMANN diferencia processos comunicativos espontâneos, pouco estandardizados, dos processos que seguem modelos fixos. Tais modelos fixos são denominados por ele como gêneros comunicativos (kommunikative Gattungen). Gêneros comunicativos influenciam o andamento de processos comunicativos, já que os gêneros normatizam tais processos.

KNOBLAUCH (2002:266) define o gerenciamento comunicativo de uma sociedade como o conjunto de todos os processos comunicativos:

[...] all jene kommunikativen Vorgänge, die einen Einfluss auf Bestand und Veränderung einer Gesellschaft ausüben. Er enthält Gattungen ebenso wie bedeutsam gewordene „spontane“ kommunikative Vorgänge, sprachliche wie nonverbale Formen der Kommunikation. Er gliedert sich nach Situationen, Institutionen und Milieus. Der kommunikative Haushalt bildet damit das Herzstïck dessen, was als Kultur bezeichnet wird. $^{18}$

A caracterização do gerenciamento comunicativo de uma sociedade perpassa, assim, pelo papel quantitativo e qualitativo que um gênero discursivo desempenha em um sistema discursivo, em uma determinada sociedade e em determinada época.

Relevante para a teoria do gerenciamento comunicativo é o papel da intertextualidade de gêneros. Assim, postula-se que há uma organização interna do

\footnotetext{
${ }^{18}$ [...] todos os processos comunicativos que exercem influência sobre a existência e mudança de uma sociedade. Ela (a economia comunicativa) comporta categorias/gêneros como também processos comunicativos espontâneos que se tornaram significativos, formas de comunicação verbais e não verbais. Ela estrutura-se segundo situações, instituições e meios. A economia comunicativa consiste, portanto, no coração do que se denomina "cultura".
} 
gênero, mas há também relações sistemáticas entre os gêneros. Nesse sentido, a caracterização e o desenvolvimento de um determinado gênero é considerado em sua interdependência com outros gêneros do mesmo campo comunicativo.

Segundo ADAMZIK, as especificidades culturais de cada gênero refletem-se especialmente nas redes de gêneros discursivos e nos sistemas discursivos que tais redes compõem. Assim, ADAMZIK propõe a análise do uso de gêneros discursivos, i.e., um olhar para além de estruturas microlingüísticas.

Dentre os principais critérios de análise sugeridos pela abordagem sociológica do gênero discursivo, desempenha um papel fundamental na presente pesquisa a ligação de gêneros discursivos em redes (Vernetztheit von Textsorten) e em sistemas discursivos (Diskurssysteme), i.e., a intertextualidade de gêneros (cf. KLEIN (2000:31-43) e ADAMZIK (2000:102-110)).

\section{Intertextualidade de gêneros discursivos}

Já em DE BEAUGRANDE \& DRESSLER (1981:138-188) é citada a intertextualidade como um dos sete critérios de textualidade. O conceito de intertextualidade tem sido utilizado a partir de perspectivas bem diferentes, dentre as quais DE BEAUGRANDE \& DRESSLER destacam as três seguintes: (i) referência a um texto (citação); (ii) textos interligados em um mesmo discurso, tais como, por exemplo, elementos que poderiam ser considerados como parte de um texto dialógico (pergunta e resposta; comentário e réplica), (iii) gêneros discursivos como estruturas ideais segundo as quais textos são construídos.

Tais perspectivas do conceito de intertextualidade destacadas por DE BEAUGRANDE \& DRESSLER dizem respeito às relações entre exemplares de texto (perspectiva I), entre partes do texto (perspectiva II) e, por fim, entre exemplar de texto e o modelo segundo o qual é construído (perspectiva III). ADAMZIK (2001:28) e KLEIN (1991) integram ao conceito de intertextualidade uma quarta perspectiva, a saber, a das relações sistemáticas entre gêneros discursivos diferentes em um mesmo campo de comunicação. Tais relações sistemáticas entre gêneros discursivos constituem uma rede de gêneros discursivos, na qual diferentes gêneros estão ligados funcionalmente. Uma determinada tarefa comunicativa (por exemplo, comprar um carro) dá ensejo à produção de gêneros discursivos diversos (anúncio de jornal, conversa com vendedor da concessionária, telefonema, dentre outros). 


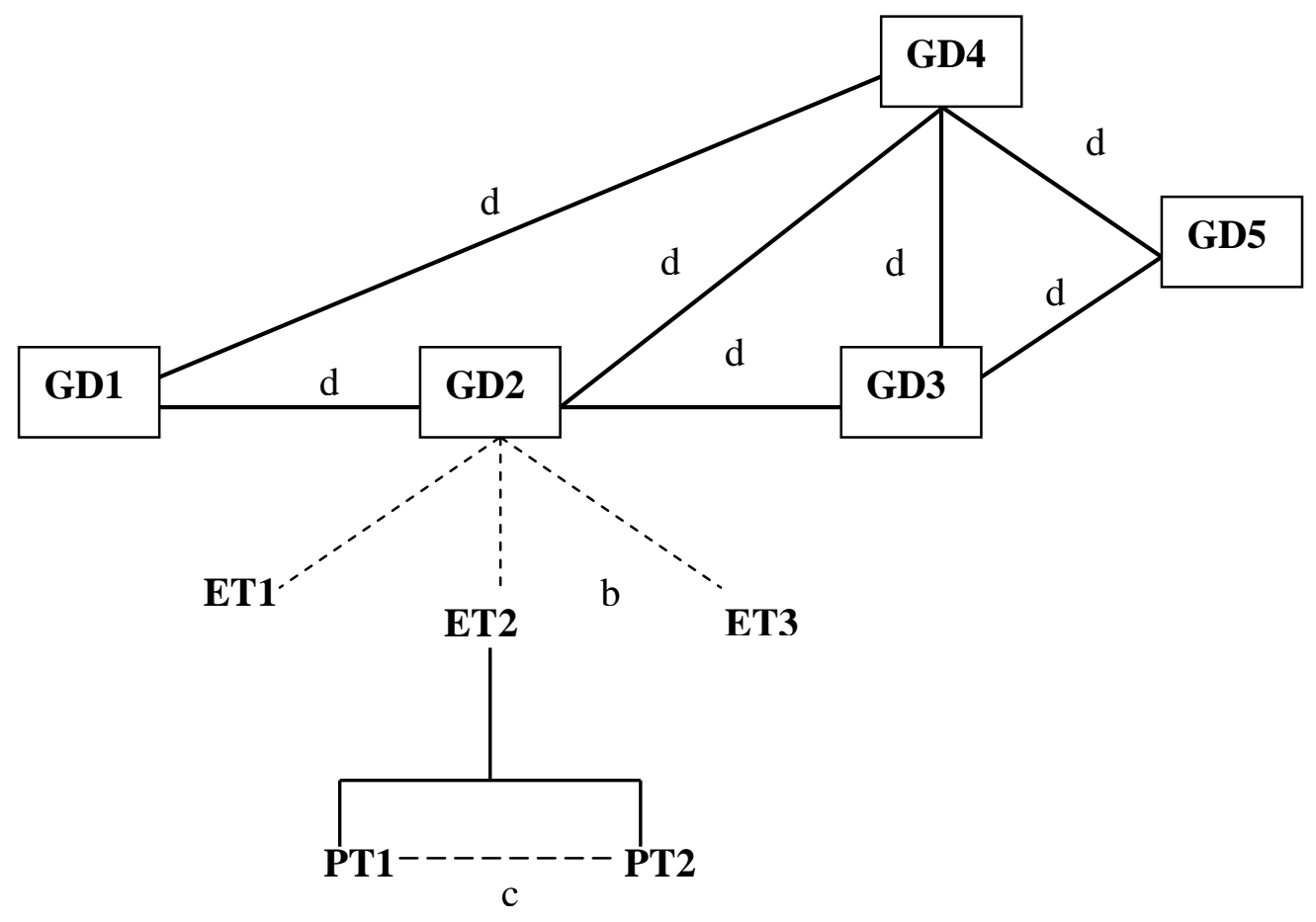

GD $=$ gênero discursivo
$\mathrm{ET}=$ exemplar de texto
$\mathrm{PT}=$ parte do texto

a: relação gênero discursivo-exemplar de texto

b: relação exemplar de texto-exemplar de texto (por ex., citação) c: relação parte do texto-parte do texto (por ex., comentárioréplica)

Figura 01: tipos de relações intertextuais (segundo KLEIN 1991: 246 e ADAMZIK 2001: 29)

KLEIN (1991:247) e ADAMZIK (2001:30) propõem, portanto, a pesquisa da ligação funcional de gêneros discursivos dentro de um sistema de interação. Tal ligação está representada na figura 3 através da relação d. Pode-se, assim, destacar um tipo de relação intertextual entre gêneros discursivos, que corresponde ao nível sintagmático (por exemplo, o resumo de comunicação em anais de congressos, o manuscrito da comunicação, a discussão, etc. e ao nível paradigmático (obituário publicado no jornal e obituário enviado por carta). A complexidade de relações intertextuais entre gêneros discursivos, que constituem uma rede, pode ser exemplificada através do gênero "telenovela" (em alemão, "Seifenopern") (ADAMZIK 2001:31) segundo KLEIN (2000): 


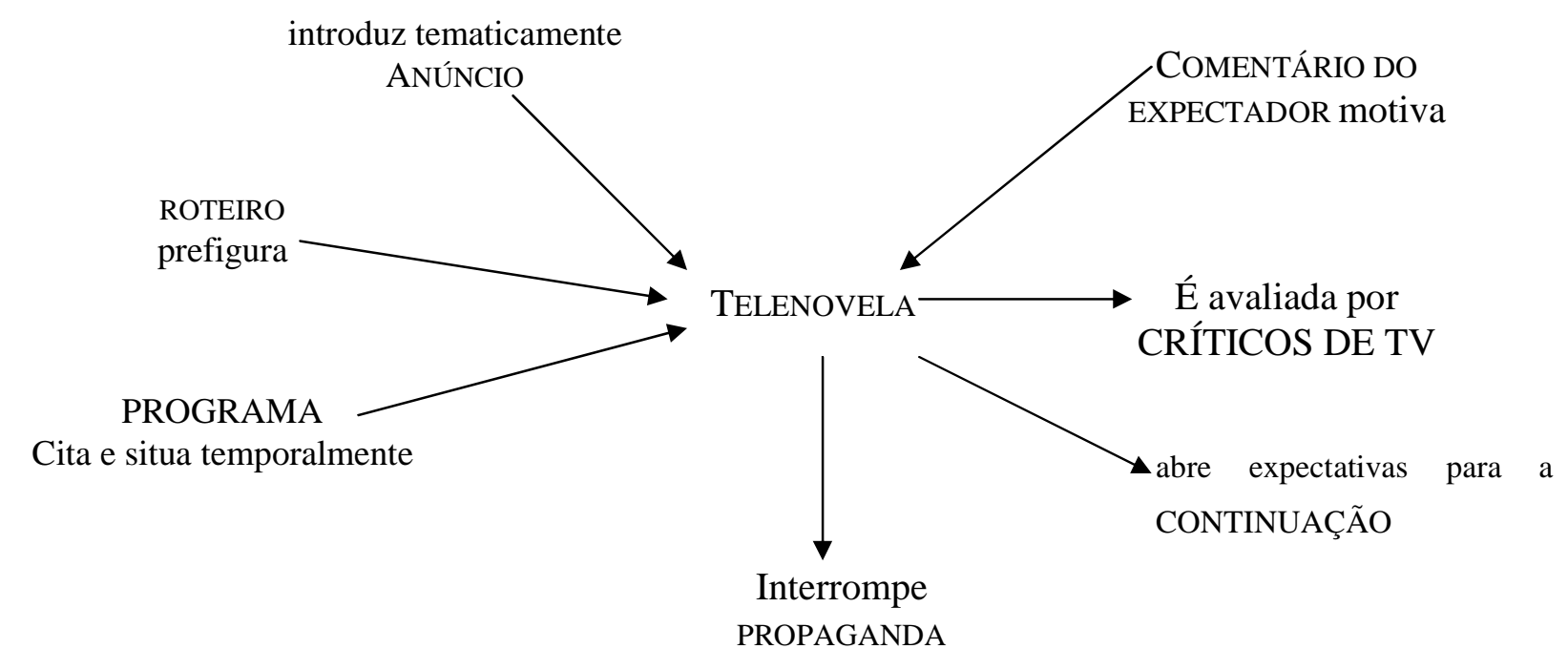

Fig. 2: Rede de gêneros discursivos (o exemplo da "telenovela" segundo J. KLEIN)

A fim de identificar o papel de um gênero discursivo na economia comunicativa de uma sociedade, deve-se considerar o papel que tal gênero desempenha em uma rede de gêneros discursivos (Textsortennetz) e sistemas discursivos (Diskurssysteme) (ADAMZIK 2002:254).

Para determinar o papel do gênero discursivo "telenovela", é decisivo saber que outros gêneros discursivos estão funcionalmente ligados à telenovela e que relevância eles tem, i.e., com que frequiência são produzidos e lidos/ouvidos/vistos, como estão ligados a outros gêneros e como diferenciam-se de outros gêneros semelhantes (por exemplo, filmes, seriados, dentro outros) (ADAMZIK 2001:31).

A seguir, serão apresentadas as redes de gêneros discursivos na produção escrita de escolares brasileiros e alemães.

\section{Redes de gêneros discursivos na produção escrita de alunos brasileiros e alemães}

Para comprovar a hipótese de que especificidades culturais do gênero podem refletir-se em uma determinada preferência na escolha de gêneros para conteúdos comparáveis, alunos brasileiros e alemães foram instados a escrever redações sobre o tema "Violência na escola"/"Gewalt in der Schule".

Os dados analisados foram levantados em salas de $8^{\mathrm{a}}$. série de três instituições escolares no Brasil e na Alemanha, a saber: Escola de Aplicação da Faculdade de Educação da USP, Escola Estadual Capitão Pedro Monteiro do Amaral e Colégio MackenzieTamboré, todas localizadas em São Paulo; Realschule Königstr., em Hamburgo, Robert- 
Jungk-Oberschule (Gesamtschule) e Königin-Luise-Stiftung (Gymnasium), ambas em Berlim.

O levantamento dos dados brasileiros e alemães seguiu parâmetros semelhantes das condições de produção dos textos (tempo de produção, tema, perfil social da escola e dos alunos, série, idade). Elaborou-se um questionário para o controle do perfil dos alunosinformantes. As aulas ministradas em todos os grupos de informantes obedeceram às seguintes etapas:

- $\quad$ Explicação dos objetivos da presente pesquisa

1. Levantamento dos dados sobre os informantes (preenchimento do questionário pelos alunos-informantes)

2. Discussão do tema para a produção de texto (Violência na escola/Gewalt in der Schule)

- $\quad$ Composição de textos pelos alunos

- $\quad$ Leitura em voz alta e discussão dos textos produzidos

Três questões nortearam as discussões do tema com os alunos:

1. Você já viveu algo assim?/Hast du schon mal so etwas erlebt?

2. De onde vem isso?/ Woher kommt das?

3. Como se pode mudar isso?/Wie könnte man das ändern?

Os alunos-informantes tiveram à sua disposição 30 minutos de composição de texto. Não foi determinado o gênero a ser produzido, antes foi dada ênfase à possibilidade de desenvolver o tema em gêneros discursivos de sua escolha. Os corpora da pesquisa são constituídos do seguinte modo:

\begin{tabular}{|c|c|c|c|}
\hline Brasil & Dados & Alemanha & Dados \\
\hline Aplicação & 20 & Realschule Königstr. & 23 \\
\hline Capitão & 21 & Gymnasium Königin- & 22 \\
\hline Mackenzie & 20 & $\begin{array}{l}\text { Luise-Stiftung } \\
\text { Robert-Jungk- } \\
\text { Oberschule }\end{array}$ & 18 \\
\hline Total & 61 & Total & 63 \\
\hline
\end{tabular}


Fig.03: descrição do corpus

Buscava-se identificar o papel de diferentes gêneros discursivos no discurso escolar no Brasil e na Alemanha. Como resultado, foram identificados em ambos corpora alguns gêneros discursivos produzidos com maior freqüência, tais como:

Brasil

$\begin{array}{lcclcl}\text { Dissertação/Erörterung } & 23 & 37,70 \% & \text { Erörterung/Dissertação } & 20 & 31,74 \% \\ \text { Relato/Bericht } & 9 & 14,75 \% & \text { Erlebnisbericht/Depoimento } & 10 & 15,9 \% \\ \text { Poema/ Gedicht } & 7 & 11,47 \% & \text { Erzählung/Narrativa } & 9 & 14,3 \% \\ \text { Página de diário/Tagebucheintrag } & 5 & 8,2 \% & \text { Bericht/ Relato } & 8 & 12,7 \% \\ \text { Depoimento/Erlebnisbericht } & 3 & 4,9 \% & \text { Schülerinterview/Entrevista com aluno } & 4 & 6,35 \% \\ \text { Narrativa/Erzählung } & 3 & 4,9 \% & \text { Gedicht/Poema } & 3 & 4,76 \%\end{array}$

Foram, ainda, produzidos alguns gêneros com menor frequiência nos dois corpora. Desse grupo fazem parte os seguintes gêneros discursivos:

\section{Brasil}

Narrativa com moral/Moralgeschicht

Carta pessoal/ privater Brief

Depoimento argumentativo Argumentativer Erlebnisbericht

Depoimento com dedicatória Erlebnisbericht mit Widmung

Depoimento com poema Erlebnisbericht mit Gedicht

Carta oficial/ öffentlicher Brief

Notícia de jornal de escola

Schulzeitungsnachricht

Notícia de jornal/Zeitungsnachricht

Entrevista com aluno/Schülerinterview

\author{
$23,28 \%$ Comicgeschichte $/ H Q$ \\ 2 3,28\% Fernseh-Interview/Entrevista de televisão \\ 1 1,63\% Experten-Interview / Entrevista com especialista \\ $1,63 \% \quad$ Rap \\ $1,63 \%$ Mitteilung / Comunicado \\ 1 1,63\% •Tagebucheintrag/Página de diário \\ 1 \\ Zeitungsnachricht / Notícia de jornal \\ $11,63 \%$ \\ $11,63 \%$
}

Alemanha

$23,2 \%$

$23,2 \%$

$11,6 \%$

$11,6 \%$

$11,6 \%$

$11,6 \%$

Quando da escolha de gêneros discursivos nos dois corpora, foram produzidos alguns gêneros discursivos somente por informantes brasileiros e outros, somente por informantes alemães, constituindo um "legado de gêneros discursivos" de cada país, como a seguir: 


\section{Brasil}

Depoimento argumentativo Argumentativer Erlebnisbericht

Depoimento com poema Erlebnisbericht mit Gedicht

História com moral/ Moralgeschichte

Carta pessoal/ privater Brief

Carta oficial/ öffentlicher Brief

Noticia de jornal de escola

Schulzeitungsnachricht

\section{Alemanha}

Comicgeschichte /HQ

Experten-Interview / Entrevista com especialista

Fernseh-Interview/Entrevista de televisão

Rap

Mitteilung / Comunicado

O quadro de distribuição de gêneros discursivos nos corpora brasileiro e alemão permite identificar semelhanças e diferenças na escolha de gêneros discursivos por brasileiros e alemães. Informantes alemães e brasileiros escolheram o gênero discursivo dissertação escolar/Erörterung com maior freqüência que outros gêneros. Tal fato pode ser debitado à conta da relevância desse gênero na prática escolar e sua representativa distribuição no discurso escolar nas duas culturas.

De uma perspectiva intercultural, pode-se apontar diferenças referentes às funções textuais dominantes dos gêneros discursivos escolhidos. Os informantes brasileiros privilegiaram a escolha de gêneros discursivos em que predominam as funções conativa e expressiva (dissertação escolar, poema, página de diário, etc.). Os informantes alemães, por sua vez, privilegiaram gêneros discursivos em que predominam as funções referencial e fática (entrevista, relato, história em quadrinhos, etc).

É relevante notar que a função conativa e a função expressiva apresentam um dado comum: elas servem a emissões de juízos. FIEHLER (1990:45) acentua o papel das emoções em juízos de valor. Segundo FIEHLER, uma parte dos atos de emissão de juízo está ligada ao nível emocional, constituindo uma forma específica de avaliação. A partir desta perspectiva, as funções conativa e expressiva podem ser consideradas ambas como meios de emissão de juízo, de expressão, portanto, de subjetividade. A distribuição de gêneros discursivos nos dois corpora parece indicar que os dados brasileiros expressam proximidade com mais frequiência que os dados alemães.

A função expressiva diferencia-se da expressão conativa, contudo, por apresentar ligação com nível emocional. Esse aspecto deverá ser considerado a seguir. De uma perspectiva social, verificam-se diferenças entre os grupos de informantes brasileiros. Observa-se que os informantes do grupo Capitão escolhem com maior frequiência gêneros discursivos apropriados à função expressiva (depoimento e poema, por exemplo), ao passo que os informantes do grupo Mackenzie produzem com maior freqüência gêneros discursivos em que predomina a função conativa (dissertação escolar). Observa-se, assim, nos dados provenientes do grupo de informantes Capitão maior expressão de afetividade que nos outros grupos, enquanto os dados do grupo Mackenzie-Tamboré expressam menor afetividade dentro do corpus brasileiro. 
No corpus alemão, também podem ser observadas diferenças entre grupos socialmente diferenciados. Os informantes do grupo Robert-Jungk-Oberschule privilegiaram gêneros discursivos narrativos (Bericht/relato, Erlebnisbericht/depoimento, Erzählung/narrativa ficcional) com função expressiva. Os informantes do grupo Königstrasse privilegiaram gêneros discursivos com função expressiva (poema, rap, página de diário, depoimento) e com função conativa (dissertação escolar). Os informantes do grupo Königin-Luise-Stiftung produziram mais gêneros com função referencial e produziram com menor freqüência que os outros dois grupos gêneros com função expressiva ou conativa.

Os grupos Mackenzie-Tamboré e Königin-Luise-Stiftung representam os setores com maiores chances de acesso ao ensino superior. Nesse sentido, pode-se explicar a menor frequiência de gêneros discursivos com função expressiva nos dados desses grupos de informantes em virtude de determinações da grade escolar. Nesses grupos, a produção de gêneros discursivos do discurso científico faz parte de preparação intensiva ao estudo em nível superior.

Alguns dos gêneros aqui produzidos poderiam ser vistos como variantes de um gênero discursivo. Desse modo, o gênero "entrevista de televisão" poderia ser considerado uma variante do gênero "entrevista". Dado que a presente pesquisa é pautada por uma perspectiva sincrônica, preferiu-se não fazer a diferenciação entre gêneros e suas variantes: parte-se aqui do princípio de que não existe algo como "a dissertação", i.e., uma forma sem variantes. Dissertação é, antes, a denominação de uma classe de variantes de gêneros discursivos de aspectos formais semelhantes. O papel a ser desempenhado por uma variante de gênero em relação a outras variantes é uma questão que deve ser comprovada. Nesse sentido, para a próxima geração, a variante "entrevista de televisão" pode tomar o papel de gênero prototípico para aquilo o que hoje denominamos somente "entrevista"

Em relação às hipóteses 1 e 2 pode-se observar que existem diferentes escolhas de gêneros discursivos. Dessas observações resulta, porém, um problema teórico: em que medida pode-se considerar que uma dissertação e uma Erörterung são gêneros correspondentes? Tal questão pode ser considerada a partir da teoria de "semelhanças familiares" ("Familienähnlichkeiten"), como concebida por WITTGENSTEIN (1996). Para que um objeto seja considerado semelhante a outro, é necessário que tenha pelo menos uma característica comum a esse segundo objeto e, ao mesmo tempo, diferencie-se dele. Isso quer dizer, que a dissertação brasileira e a Erörterung alemã podem ser consideradas como gêneros discursivos da mesma família — desde que ambas tenham algumas características em comum.

A título de comparação, apontemos algumas semelhanças e diferenças entre uma típica dissertação do corpus brasileiro e de uma típica Erörterung do corpus alemão ${ }^{20}$.

\section{Modos típicos de uso de gêneros discursivos}

\footnotetext{
${ }^{19}$ Em estudos sobre o gênero entrevista já se faz distinção entre variantes, tais como entrevista de rádio, entrevista de televisão, entrevista impressa. Entretanto, não se pode ainda identificar a variante a ser considerada como forma prototípica do gênero discursivo pelo falante do português brasileiro.

${ }^{20}$ Os dados foram digitados de modo fiel ao texto original.
} 


\title{
5.1. Modos típicos de uso: o exemplo da dissertação e da Erörterung
}

Os textos a seguir podem ser considerados como representativos dos dados que constituem o corpus brasileiro e o corpus alemão.

\section{Uma Erörterung alemã} -Gesamtschule Robert-Jungk-Oberschule 07-8A-2004-15 anos- feminino- 138
palavras

\author{
Violência na escola" $\quad$ 10.5.04
}

Eu nunca vivi uma violência dessa na escola. Mas se eu visse algo assim, eu interviria ou buscaria um professor e tentaria separá-los. Algumas crianças ou alunos são tão brutais, porque depois da escola eles assistem Anime demais e jogam muitos jogos de guerra. Hoje em dia passam muitos filmes brutais na televisão. Alguns não conseguem separar filme de realidade.

Que haja violência na escola, não se pode evitar, entretanto se poderia limitá-la, falando-se com os pais das crianças. Em geral, o problema é os pais, quando as crianças não tem um bom lar. Só apanham em casa e tem de ver como o pai bate na mãe. Como as crianças pensam que os pais são exemplos no momento elas fazem a mesma coisa na escola.

\section{Uma dissertação brasileira}

•EECPMA 14-8B-2003-14 anos-masculino-249 palavras

\author{
Produção de Texto \\ Tema: "Violência na Escola"... Chega
}

Pelo pouco que vivi e estou apressenciar, existe varios tipos de violência, não que eu vivi, mas pelo que eu vejo e observo, vou comentar como as pessoas se demonstram diante da violência e o que fazem para solucionar o problema.

$\mathrm{Na}$ escola particularmente, as pessoas não se respeitam mais, não são tolerantes, o amor não existe. A paz está cada vez mais distante de nós, existe o vandalismo, o preconceito, o desrespeito, tudo o que há de ruim parece estar presente entre nós, isso teria que ter um fim, mas o problema não é fácil de resolver, os governantes tem culpa, mas nos também temos pois o que fazemos para melhorar o ambiente em que vivemos, no lugar onde nos desejamos aprender e sairmos verdadeiros cidadões, mas como as coisas andam muitos saem daqui para pregar mais e mais a violência, saem piores deste ambiente. 
A violência vem de cada um, vem de nós, de pessoas que não encontraram o amor, a compreensão, carinho e que necessitam de amor, poderia ficar horas e horas desabafando, contando como a violência está presente entre nós.

Como resolver o problema da violência, como tirar as drogas que praticamente dominam a escola, como e a pergunta que eu queria encontrar resposta, como acabar com a violência, como?

O melhor seria um novo modo de ensino, melhores salários para os professores, melhores salários, mais investimentos e mais conscientização de cada um que usufrui da escola, bem foi isso.

Destaquemos apenas alguns dos critérios utilizados na análise desses dois textos: as funções textuais, os modelos de argumentação, os juntores e as expressões do campo semântico da violência.

A Erörterung alemã desempenha duas principais funções textuais: é um gênero informativo e argumentativo. A dissertação brasileira, por sua vez, desempenha não somente uma função informativa e argumentativa, mas também expressiva (emotiva). Também em relação aos modelos de argumentação usados podem ser encontradas diferenças. A argumentação na Erörterung é baseada nos topoi da imitação e da agressão, i.e., argumenta-se que os pais e a televisão ensinam a violência às crianças. Como solução são sugeridas estratégias concretas de superação de conflito, tais como a conversa com um professor. A Erörterung volta-se, sobretudo, às causas da violência. Quanto aos meios lingüísticos utilizados nesse contexto, deve-se destacar o papel de determinados juntores. A expressão de concessividade nas Erörterungen presentes no corpus alemão está relacionada à escolha dos modelos de argumentação.

$\mathrm{Na}$ dissertação, a argumentação baseia-se em conceitos abstratos do topos do preconceito e do topos social, tanto no esclarecimento de causas como na busca de soluções para o problema da violência. As dissertações tematizam soluções para o problema da violência com maior freqüência que as Erörterungen, o que contribui para a maior expressão de finalidade nas dissertações do corpus brasileiro, traço lingüístico característico do grupo.

Na utilização de expressões pertencentes ao campo semântico da violência, notase na Erörterung uma predominância de expressões do campo da violência corporal, ao passo que a dissertação tematiza a violência corporal e deixa implìcita uma violência estrutural, ou seja, social.

Assim, a análise dos dados parece indicar que os gêneros Erörterung e dissertação diferenciam-se em relação aos conhecimentos ativados, aos meios lingüísticos escolhidos e a suas tarefas comunicativas, comprovando a hipótese de que existem usos típicos de gêneros em determinadas culturas. 


\section{2 Modos típicos de uso de gêneros discursivos em grupos sociais diversos}

Propomo-nos, porém, dar um passo a mais, verificando o uso de gêneros discursivos não somente em duas culturas diferentes, mas também em grupos sociais diferenciados. Para tanto, apresentamos aqui a análise dos dados segundo o critério do campo semântico das expressões da violência sensorialmente experenciada (EVSE). Esse campo abrange apenas expressões da violência observada ou vivenciada pelos próprios alunos, tais como insultar, bater, ameaçar, zoar, espancar, pancadaria, etc. A vivência sensorial da violência pode ser representada a partir de três perspectivas:

\section{-Perspectiva de autor:}

Em forma de soco, tapa, todo dia pelo menos um eu espancava. (Aplicação 01)

\section{-Perspectiva de vítima:}

Não tem o que fazer, me bateram e foram embora, e se eu abrir a boca, apanho de novo! (Capitão 06)

\section{-Perspectiva de observador:}

[...] outros meninos da escola, pegaram a cadeira no intervalo entre as aulas, chutaram, pularam em cima, jogaram ela pelo corredor, no final quando fomos ver a cadeira estava completamente destruida. (Mackenzie 02)

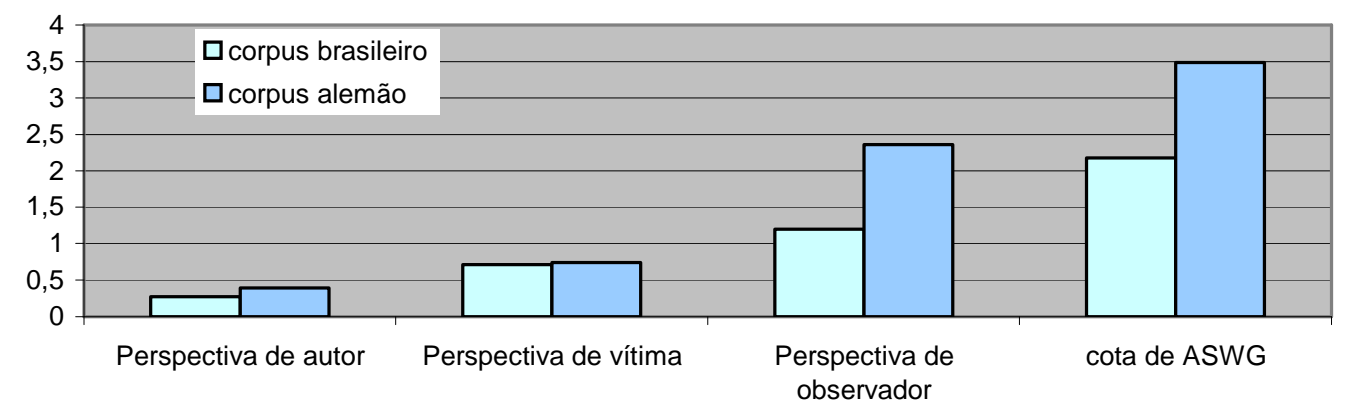

Fig. 04: Distribuição das Expressões da Violência Sensorialmente Experienciada nos dois corpora 
O gráfico acima especifica a distribuição das EVSE nos dois copora.

Inicialmente, observa-se que os informantes alemães utilizaram expressões da violência sensorialmente experenciada com maior freqüência que os informantes brasileiros. Isso não quer dizer que os informantes alemães vivenciam maior violência que os informantes brasileiros. Trata-se aqui da expressão da percepção da violência. $\mathrm{O}$ tema da violência no corpus alemão mobiliza com maior freqüência expressões do campo semântico da violência experienciada.

BIBER (1986) utiliza como critério para diferenciação de gêneros discursivos o tipo de conteúdo a ser expressado. Conteúdos abstratos motivam a produção de gêneros discursivos como a dissertação escolar, pro exemplo. Conteúdos concretos são mais adequados a gêneros discursivos narrativos, por exemplo. Seguindo BIBER, pode-se incluir a utilização de expressões da violência experenciada na escala de gêneros discursivos entre conteúdos concretos e abstratos:

conteúdo abstrato (menos expressões da violência experienciada)

$$
\mid \begin{aligned}
& \text { dissertação escolar/Erörterung } \\
& \text { relatório/Bericht } \\
& \text { Narrativa ficcional/Erzählung }
\end{aligned}
$$

Observa-se, portanto, no gráfico acima que os dados de informantes brasileiros apresentam conteúdo mais abstrato e os dados de informantes alemães, conteúdo mais concreto.

Informantes alemães e brasileiros escolheram a perspectiva de observador com maior freqüência que as outras. Entretanto, proporcionalmente os informantes brasileiros escolheram as perspectivas de autor e vítima com frequiência maior: cerca da metade das expressões da violência experienciada no corpus brasileiro encaixa-se nas perspectivas de autor e vítima. No corpus alemão, 1/3 delas é utilizado nessas mesmas perspectivas.

Assim, de um lado, os dados brasileiros podem ser caracterizados como menos situados, quer dizer mais independentes do contexto, e mais abstratos, dado que utilizam menos expressões da violência experienciada. Por outro lado, os dados brasileiros expressam maior envolvimento, i.e., subjetividade, dado que as pesrpectivas de autor e vítima ocorrem com maior freqüência.

Consideremos, agora, a distribuição das expressões da violência experienciada em cada um dos grupos de informantes: 
Distribuição das expressões do campo semântico da violência percebida sensorialmente no corpus alemão

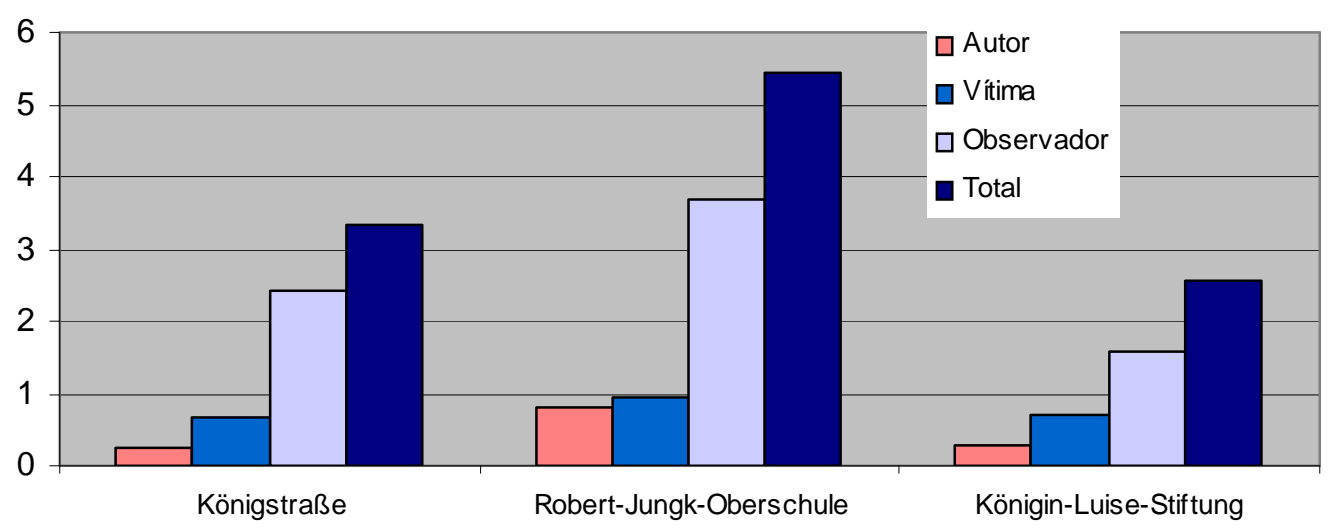

Fig. 06: Distribuição da EVSE no corpus alemão.

No corpus alemão, destaca-se a utilização das perspectivas de autor e vítima com freqüência maior no grupo de informantes da Robert-Jungk-Oberschule. Nos dados do grupo Königin-Luise-Stiftung, o uso de expressões do campo semântico da violência percebida sensorialmente é menor que nos outros dois grupos. No corpus brasileiro, as perspectivas de autor e vítima ocorrem com maior freqüência nos dados dos informantes da escola Capitão e com menor freqüência nos dados provindos do Colégio Mackenzie. Nesse último grupo, observa-se a menor freqüência de expressões da violência percebida sensorialmente.

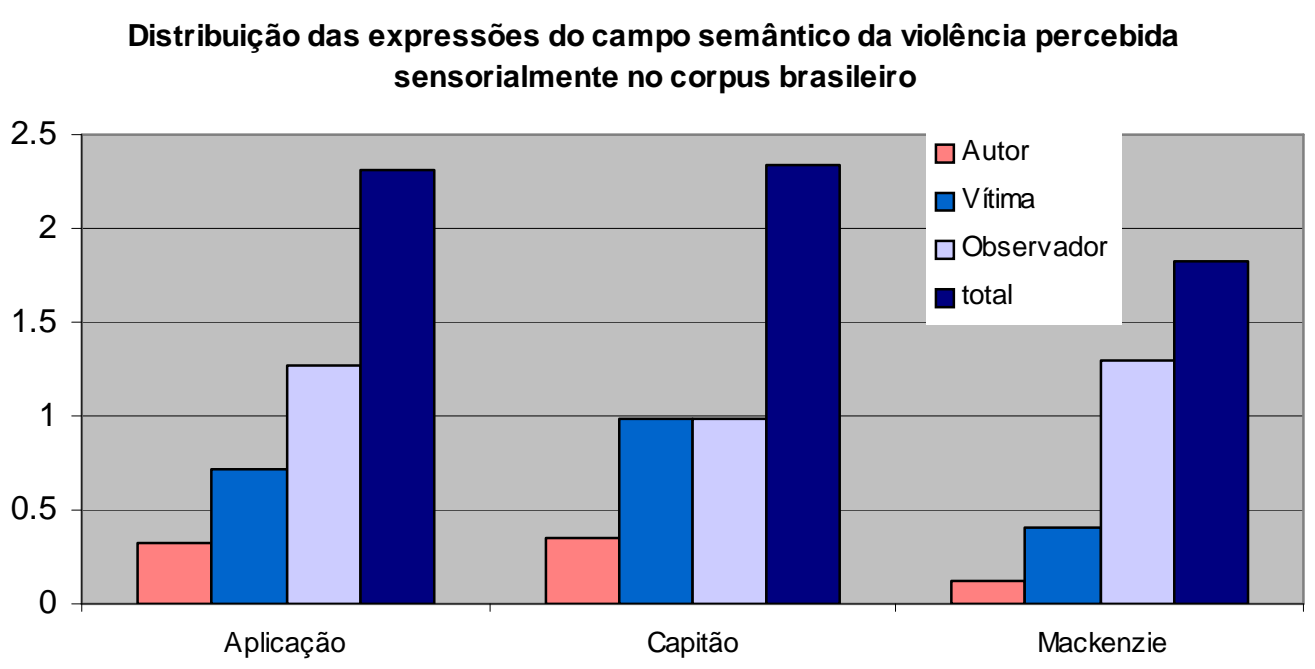

A menor freqüência de expressões da violência percebida sensorialmante no grupo Mackenzie-Tamboré, no corpus brasileiro, e no grupo Königin-Luise-Stiftung, no corpus 
alemão pode ser relacionada a dois fatores principalmente. Como dito anteriormente, os informantes desses grupos são preparados para o ensino superior. Nesse contexto, a produção de gêneros discursivos de conteúdo abstrato desempenha um papel relevante. Entretanto, pode-se ainda questionar, se o tipo de instituição escolar está ligada ao tipo de experiência com a violência e, conseqüentemente, ao modo de expressão lingüística da violência. Em outras palavras: os informantes dos grupos Mackenzie-Tamboré e KöniginLuise-Stiftung têm menor experiência com a violência e por isso utilizam menos expressões do campo semântico da violência percebida sensorialmente? Ou utilizam tais expressões com menor frequiência em virtude da grade curricular diferenciada, voltada à preparação para o ensino superior e, conseqüentemente, para o domínio de gêneros discursivos do discurso científico?

A partir dessas observações e questionamentos, podemos comprovar que existem, de um lado, diferenças dentro de uma cultura e, por outro lado, semelhanças entre culturas, como observadas nos dados dos informantes brasileiros e alemães.

\section{Considerações finais}

Parte dos demais resultados obtidos parece confirmar alguns clichês e preconceitos existentes entre Brasil e Alemanha, como, por exemplo, o clichê da tensão proximidadedistância.

Com relação a essa tensão, observou-se que os informantes brasileiros expressam maior subjetividade, tematizam a própria identidade (Selbstbild) e utilizam uma concepção oral de texto. Os informantes alemães expressam maior objetividade, tematizam a alteridade (Fremdbild) e a concepção de seus textos é escrita.

Porém, outros resultados identificados surpreendem e parecem contradizer alguns clichês. Mesmo indicando maior proximidade, i.e., subjetividade, os dados brasileiros ainda assim revelam, de outra perspectiva, uma abordagem do tema mais global, mais teórica e mais voltada às soluções, enquanto nos dados alemães é dada preferência a uma abordagem do tema mais pontual, presa aos fatos concretos e orientada às causas.

Por fim, é necessário que discutamos os resultados, retomando as três hipóteses iniciais. Os resultados da análise mostraram que o uso e a aquisição de gêneros discursivos é marcada cultural- e socialmente. Essa hipótese pôde ser comprovada a partir de três observações. Primeiramente, foram detectadas preferências diferentes nas escolhas de gêneros discursivos por informantes brasileiros e alemães. Em segundo lugar, a análise mostrou que informantes brasileiros e alemães usaram gêneros até então considerados idênticos (como a dissertação e a Erörterung) de formas diferentes. Finalmente, observaram-se diferenças sociais intraculturais e semelhanças interculturais no uso desses gêneros.

Por fim, cabe-nos, ainda, ressaltar algumas das contribuições de nossos resultados aos Estudos do Texto e do Gênero. A partir da comprovação do condicionamento cultural e social do uso e da escolha de gêneros discursivos, podemos pleitear por uma interculturalidade do uso e da escolha do gênero: o uso e a escolha de gêneros discursivos 
são cultural e socialmente específicos e constituem, por isso, objetos interculturais relevantes.

Pleiteamos, ainda, pela necessidade de vinculação de estudos interculturais de gêneros a estudos sociológicos, dado que culturas não são homogêneas, antes se caracterizam por subculturas. Disso resulta que uma análise intercultural deve considerar especificidades sociais de uma determinada cultura.

\section{Referências bibliográficas}

ADAM, Jean-Michel (1990): Élements de linguistique textuelle. Liége: Mardaga. (1992): Les textes: Types et prototypes. Paris Nathan-Université.

ADAMZIK, Kirsten $\left(2000^{a}\right)$ : "Was ist pragmatisch orientierte Textsortenforschung?" In: ADAMZIK, Kirsten (Hrsg.): Textsorten: Reflexionen und Analysen. Tübingen: Stauffenburg, 91-112.

(2000b): Textsorten. Reflexionen und Analysen. Tübingen: Stauffenburg.

(2001a): „Die Zukunft der Textsortenlinguistik. Textsortennetze, Textsortenfelder, Textsorten im Verbund“. In: FIX, Ulla; HABSCHEID, Stephan; KLEIN, Josef (Hrsg.): Zur Kulturspezfik von Textsorten. Tübingen: Stauffenburg, 15-30.

(2001b): Kontrastive Textologie. Untersuchungen am Beispiel deutscher und französischer Sprach- und Literaturwissenschaft. Tübingen

$\left(2002^{a}\right)$ : "Interaktionsrollen. Die Textwelt und ihre Akteure". In: ADAMzIK, Kirsten (Hrsg.): Texte - Diskurse - Interaktionsrollen. Analysen zur Kommunikation im öffentlichen Raum. Tübingen: Stauffenburg, 211-255.

(2002b): Kontrastive Textologie. In: DRESCHER, Martina (Hrsg.): Textsorten im romanischen Sprachvergleich. Tübingen: Stauffenburg, 253-255.

ANTOS, Gerd (1997): "Texte als Konstitutionsformen von Wissen. Thesen zu einer evolutionstheoretischen Begründung der Textlinguistik“. In: ANTOS, G. \& TIETZ, H. (Hrg.): Die Zukunft der Textlingusitik. Traditionen, Transformationen, Trends. Tübingen: Niemeyer, 43-63.

BAKHTIN, Michail Michajlovic (1953): Estética da criação verbal. São Paulo, Martins Fontes, 1992.

BEAUGRANDE, Robert-Alain de \& DRESSLER, Wolfgang Ulrich (1981): Einführung in die Textlinguistik. Tübingen: Niemeyer.

BhatiA, Vijay Kumar (1997): "Genre analysis today". Revue Belge de Philologie et d’Histoire. Bruxelles : 75, 629-652.

BIBER, Douglas (1986): "Spoken and written textual dimensions in English: resolving the contradictory findings". In: Language, 62, 384-414. 
BRASIL. Ministério da Educação e do Desporto (1998): Parâmetros Curriculares Nacionais: $3^{\circ}$. E $4^{\circ}$. Ciclos do ensino Fundamental. Língua Portuguesa. Brasília: $\mathrm{MEC} / \mathrm{SEF}$.

(1997): Parâmetros Curriculares Nacionais: $1^{\circ}$. E $2^{\circ}$. Ciclos do ensino Fundamental. Língua Portuguesa. Brasília: MEC/SEF.

BronCKART et al. (1985): Le fonctionnement des discours. Paris, Lausanne: Delachaux \& Niestlé.

BroncKart, J.P. \& SCHNeuwly, B. (1985): Vygotsky aujourd'hui. Paris: Delachaux \& Niestlé,.

BRONCKART, J.-P. (1995): "Du behaviorisme à l'interactionisme social”. In: Des animaux et des hommes : hommage à Marc Richelle, Paris : PUF.

CAstilho DA Costa, Alessandra (2005): Sozial- und kulturspezifischer Textsortengebrauch. Ein Vergleich brasilianischer und deutscher Schüleraufsätze. Tese de doutorado defendida na Área de Lingüística Germânica da Martin-Luther-Universität Halle-Wittenberg. Disponível em: http://baru.ibict.br/tede-ibict/tde_arquivos/1/TDE-200509-30T06:21:47Z-297/Publico/AlessandraCastilhoFCosta.pdf

DRESCHER, Martina (2002): Textsorten im romanischen Sprachvergleich. Tübingen: Stauffenburg.

DREWNOWSKA-VARGÁNÉ, Ewa (2001): "Emotionalität und Narrativität in deutsch-, polnisch und ungarischsprachigen Leserbriefen im textlinguistischen Vergleich“. In: Cirko, Leslaw (Hrsg.): Studia Linguistica. Acta Universitatis Wratislaviensis XX, No 2296. Wrocaw: Universitätsverlag 2001, S. 49-64.

FAIRCLOUGH, Norman (1992): Critical Language Awareness. London [u.a.]: Longman.

FIEHLER, Reinhard (1990): Kommunikation und Emotion. Theoretische und empirische Untersuchungen zur Rolle der Emotion in der verbalen Interaktion. Berlin: de Gruyter.

FIX, Ulla; HABSCHEID, Stephan; KLEIN, Josef (2001): Zur Kulturspezifik von Textsorten. Stauffenburg.

HeInEMANN, Wolfgang \& VIEHWEGER, Dieter (1991): Textlinguistik: eine Einführung. Tübingen: Niemeyer.

KAISER, Dorothee (2002): Wege zum wissenscahftlichen Schreiben: Eine kontrastive Untersuchung zu studentischen Texten aus Venezuela und Deutschland. Stauffenburg-Verl.

KIENPOINTNER, Manfred (1992): Alltagslogik. Struktur und Funktion von Argumentationsmustern. Stuttgart/Bad Cannstatt.

KleIN, Josef (1991): "Politische Textsorten". In: BRINKER, Klaus (Hg.): Aspekte der Textlinguistik. Hildesheim 1991, 245-278.

(2000): "Intertextualität, Geltungsmodus, Texthandlungsmuster. Drei vernachlässigte Kategorien der Textsortenforschung — exemplifiziert an politischen und medialen Textsorten". In: ADAMZIK, Kirsten (Hrsg.): Textsorten: Reflexionen und Analysen. Tübingen:Stauffenburg, 31-44. 
KNOBLAUCH, Hubert (2002): "Kommunikative Gattungen". In: DreSCHER, Martina (Hrsg.): Textsorten im romanischen Sprachvergleich. Tübingen: Stauffenburg, 263-266.

Koch, Ingedore Villaça (1999a): "O Desenvolvimento da Lingüística Textual no Brasil". In: DELTA, Vol. 15, $\mathrm{N}^{\mathrm{o}}$ Especial, (2001): “Lingüística Textual: Quo vadis?”. In: DELTA, 17-Especial, 11-23.

LuCKMANN, Thomas (1988): „Kommunikative Gattungen im kommunikativen Haushalt einer Gesellschaft“. In: Gisela Smolka-Koerdt; Peter M. Spangenberg \& Dagmar TillmannBartylla (Hg): Der Ursprung von Literatur. Medien, Rollen, Kommunikationssituationen zwischen 1450 und 1650. München, 1988, 279-288.

RAIBLE, Wolfgang (1992): Junktion. Eine Dimension der Sprache und ihre Realisierungsformen zwischen Aggregation und Integration. Heidelberg (Winter) (Sitzungsberichte der Heidelberger Akademie der Wissenschaften. phil.-hist. Klasse, Jg. 1992, Bericht 2.

RoLF, Eckhard 1993: Die Funktionen der Gebrauchstextsorten. Berlin/Ney York, de Gruyter

SANDIG, Barbara (1972): "Zur Differenzierung gebrauchssprachlicher Textsorten im Deutschen". In: Elisabeth GüLICH/Wolfgang RAIBLE (Hg.) 1972: Textsorten. Differenzierungskriterien aus linguistischer Sicht. Frankfurt, 113-124.

SCHNEUWLY, B. (1985): "La construction sociale du langage écrit chez I'enfant". In SCHNEUWly, B., BRONCKART, J.-P (Eds.): Vygotsky aujourd'hui. Neuchâtel: Delachaux \& Niestlé, 1985. p. 169-202.

(1993) "Genres et types de discours: considérations psychologiques et ontogenétiques“. In Les interactions lecture-écriture:155-173. Suisse: Peter Lang. 1993.

(1995): "La transposition didactique. Réflexions du point de vue de la didactique du français langue maternelle“. In J.-L. Chiss, J. David \& Y. Reuter (Éd.), Didactique du français, états des lieux, Paris : Nathan, p. 47-62.

SWALES, J. M. (1990): Genre analysis: English in academic and research settings. Cambridge. Cambridge University Press.

VAN DIJK, Teun (1980): Textwissenschaft: Eine interdisziplinäre Einführung. München: DTV.

WARNKE, Ingo (2001): "Intrakulturell versus interkulturell - zur kulturellen Bedingtheit von Textmustern“. In: FIX, Ulla; HABSCHEID, Stephan \& KlEIN, Josef (Hrsg.): Zur Kulturspezifik von Textsorten. Tübingen: Stauffenburg, 241-254.

(2002): "Texte in Texten — Poststrukturalistischer Diskursbegriff". In: ADAMZIK, Kirsten (Hrsg.): Texte - Diskurse - Interaktionsrollen. Analysen zur Kommunikation im öffentlichen Raum. Tübingen: Stauffenburg, 1-17.

WENGELER, Martin (1997): “Argumentation im Einwanderungsdiskurs. Ein Vergleich der Zeiträume 1970-1973 und 1980-1983“. In: Martin JunG, Martin WENGELER \& Karin BöKE (Hg.): Die Sprache des Migrationsdiskurses. Das Reden über Ausländer in Medien, Politik und Alltag. Opladen 1997, 121-149. 
WitTGenstein, Ludwig (1996): Familienbriefe. Wien : Hölder-Pichler-Tempsky, 1996

\begin{abstract}
This paper presents the results of an investigation, developed by Castilho da Costa (2005), on the social-culturally specific use of text genres by Brazilian and German students from social different schools. The research seeks to answer the question: How do Brazilian and German students choose, use and "form" which text genres when they communicate about same or similar contents? The study is based on an analysis model of the text genres as cultural entities which are structured in three dimensions: linguistic, cognitive and pragmatic. At the data analysis stage, criteria were selected for the identification of the linguistic means chosen by the informers (linguistic dimension) and of the knowledge activated by the production of text genres (cognitive dimension) when fulfilling a communicative task (pragmatic dimension). In the present paper some of those criteria are presented: text genre selections by German and Brazilian, text functions, argument types, words from the semantic field of the sensorial perceived violence, finality and concessivity. The results show that the use of text genres by Brazilian and German students is determined by cultural and social parameters such as proximity/distance, abstract/concrete content and others. For the Text and Text Genres Studies, the research contributes with the confirmation of an interculturality of the text genres choices.
\end{abstract}

Keywords: Text Linguistics, text, text genre, culture. 